Supplement of Atmos. Chem. Phys. Discuss., 15, 28361-28393, 2015

http://www.atmos-chem-phys-discuss.net/15/28361/2015/

doi:10.5194/acpd-15-28361-2015-supplement

(C) Author(s) 2015. CC Attribution 3.0 License.

(c) (i)

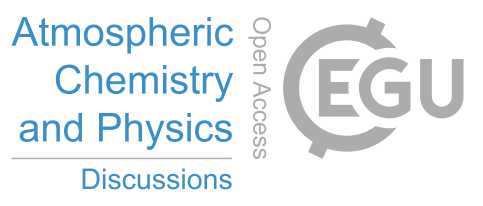

Supplement of

\title{
Using proxies to explore ensemble uncertainty in climate impact studies: the example of air pollution
}

V. E. P. Lemaire et al.

Correspondence to: V. E. P. Lemaire (vincent.lemaire-etudiant@ineris.fr)

The copyright of individual parts of the supplement might differ from the CC-BY 3.0 licence. 


\section{Mid Europe}
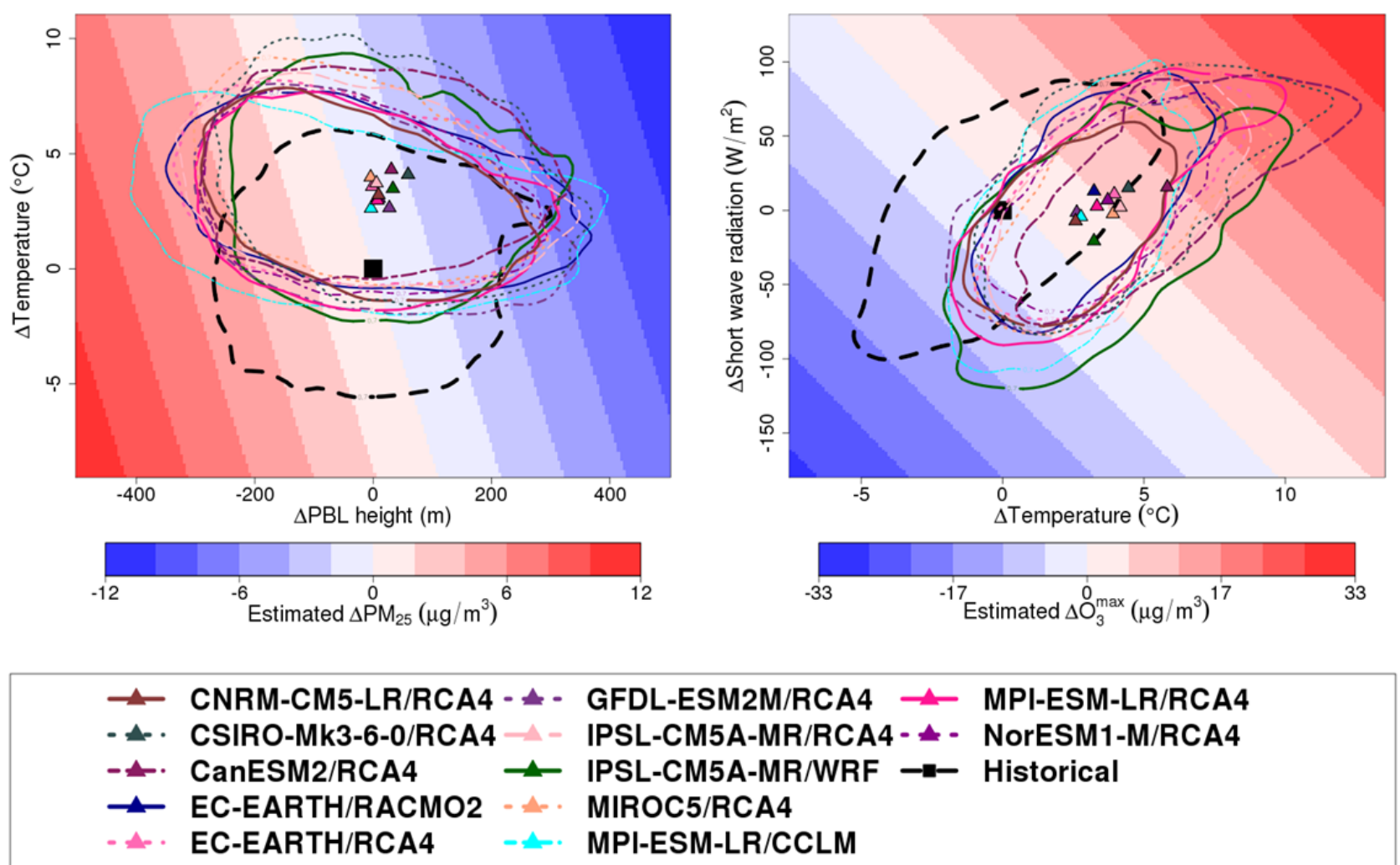

3 Figure S1: The left figure presents the proxy of ensemble projections for daily average de-seasonnalised PM2.5 concentrations in Mid Europe. The right figure represents the proxy for daily maximum deseasonnalised summer ozone for Mid Europe. For both figures, the shaded background represents the evolution of pollutants estimated by the statistical models. The contours are representing the regional climate projections and the triangles their mean. The black dashed contour represents the historical IPSL-CM5A-MR/WRF - and the square its mean. 

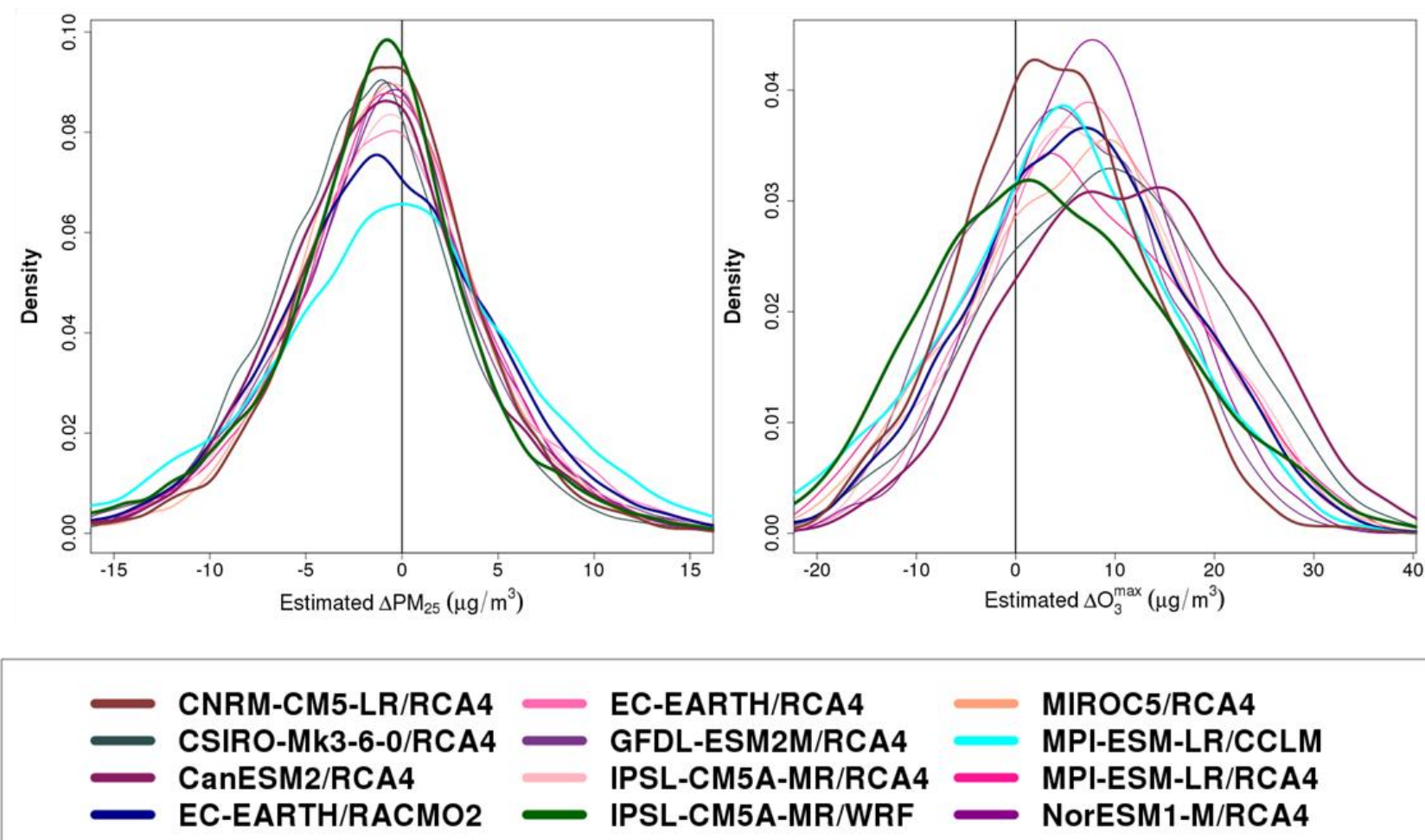

2 Figure S2: The left figure represents, for each regional climate model the probability density function 3 (PDF) of the concentrations estimated with the bivariate linear model at the end of the century minus the 4 estimated concentrations of the historical period for daily average de-seasonnalised PM2.5 concentrations in Mid Europe. The right figure presents the results for daily maximum de-seasonnalised summer ozone for Mid Europe. 

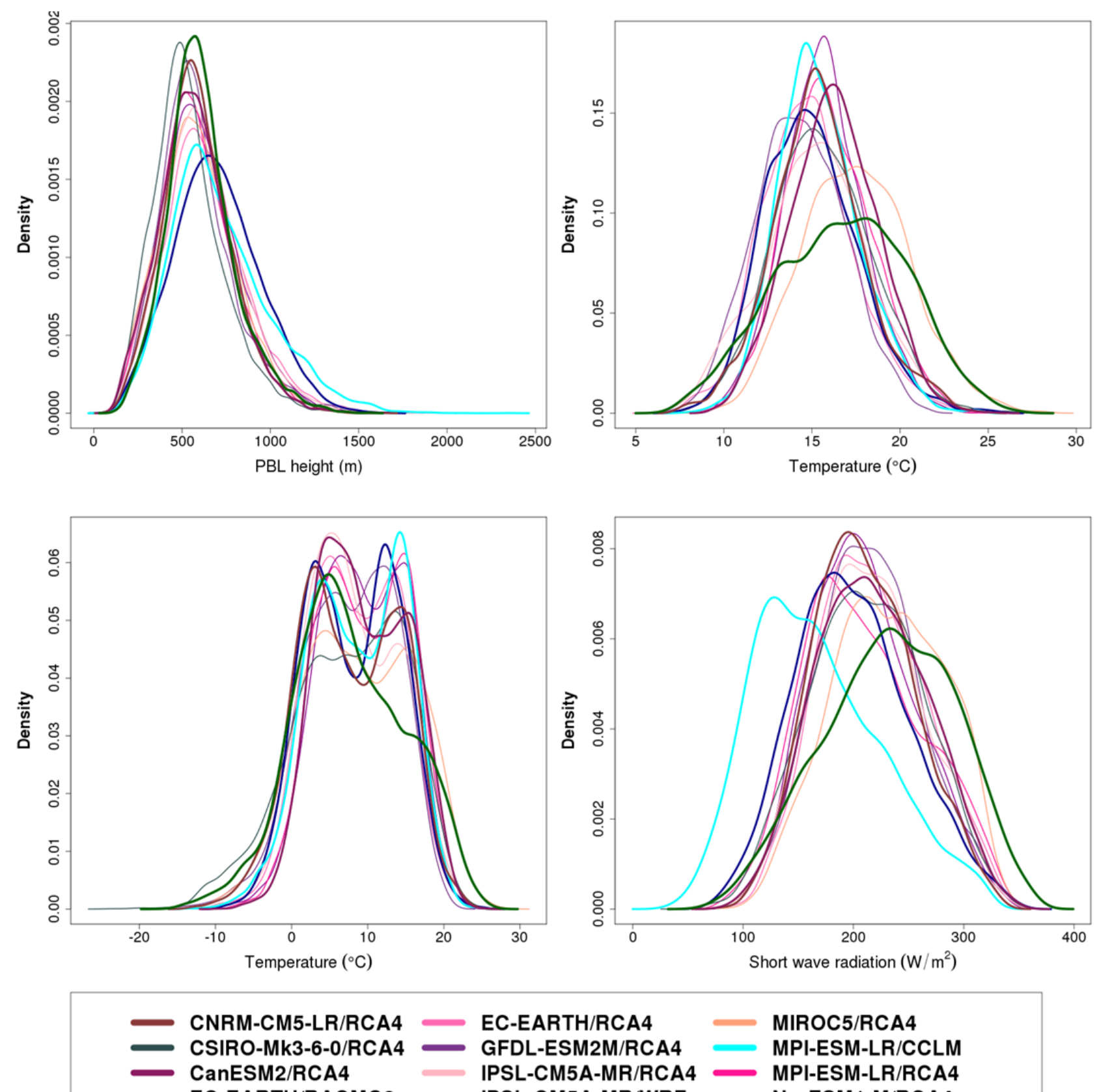

EC-EARTH/RCA4

MIROC5/RCA4

CSIRO-MK3-6-0/RCA4 - GFDL-ESM2M/RCA4

EC-EARTH/RACMO2

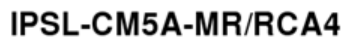

MPI-ESM-LR/CCLM

IPSL-CM5A-MR/RCA4
IPSL-CM5A-MR/WRF

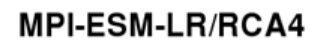

NorESM1-M/RCA4

3 Figure S3: The first column of the panel represents the historical distribution of the meteorological

4 variables identified by our statistical models as the two major drivers (a. PBL Height; b. near surface

5 temperature) for PM2.5 in Mid Europe. The second column represents the historical JJA distribution of

6

the two main drivers for summer ozone (a. near surface temperature; b. specific humidity). 


\section{Northen Italy}
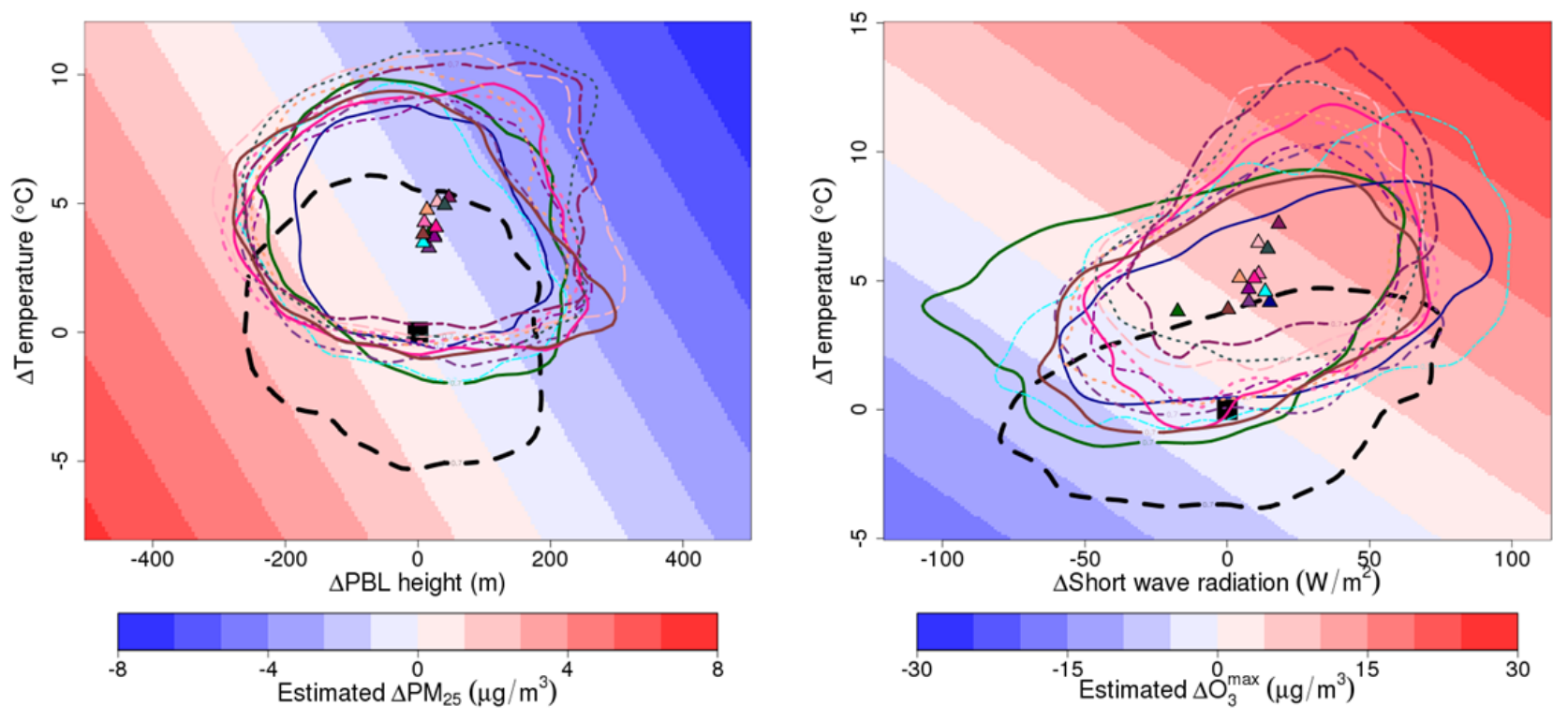

\begin{tabular}{|c|c|c|c|}
\hline $\begin{array}{l}-\Perp \\
-\Perp \\
-\Perp\end{array}$ & $\begin{array}{l}\text { CNRM-CM5-LR/RCA4 - - } \\
\text { CSIRO-MK3-6-0/RCA4 } \\
\text { CanESM2/RCA4 } \\
\text { EC-EARTH/RACMO2 } \\
\text { EC-EARTH/RCA4 }\end{array}$ & $\begin{array}{l}\text { GFDL-ESM2M/RCA4 - } \\
\text { IPSL-CM5A-MR/RCA4- } \\
\text { IPSL-CM5A-MR/WRF -- } \\
\text { MIROC5/RCA4 } \\
\text { MPI-ESM-LR/CCLM }\end{array}$ & $\begin{array}{l}\text { MPI-ESM-LR/RCA4 } \\
\text { NorESM1-M/RCA4 } \\
\text { Historical }\end{array}$ \\
\hline
\end{tabular}

3 Figure S4: Same as S1 for Northern Italy. 

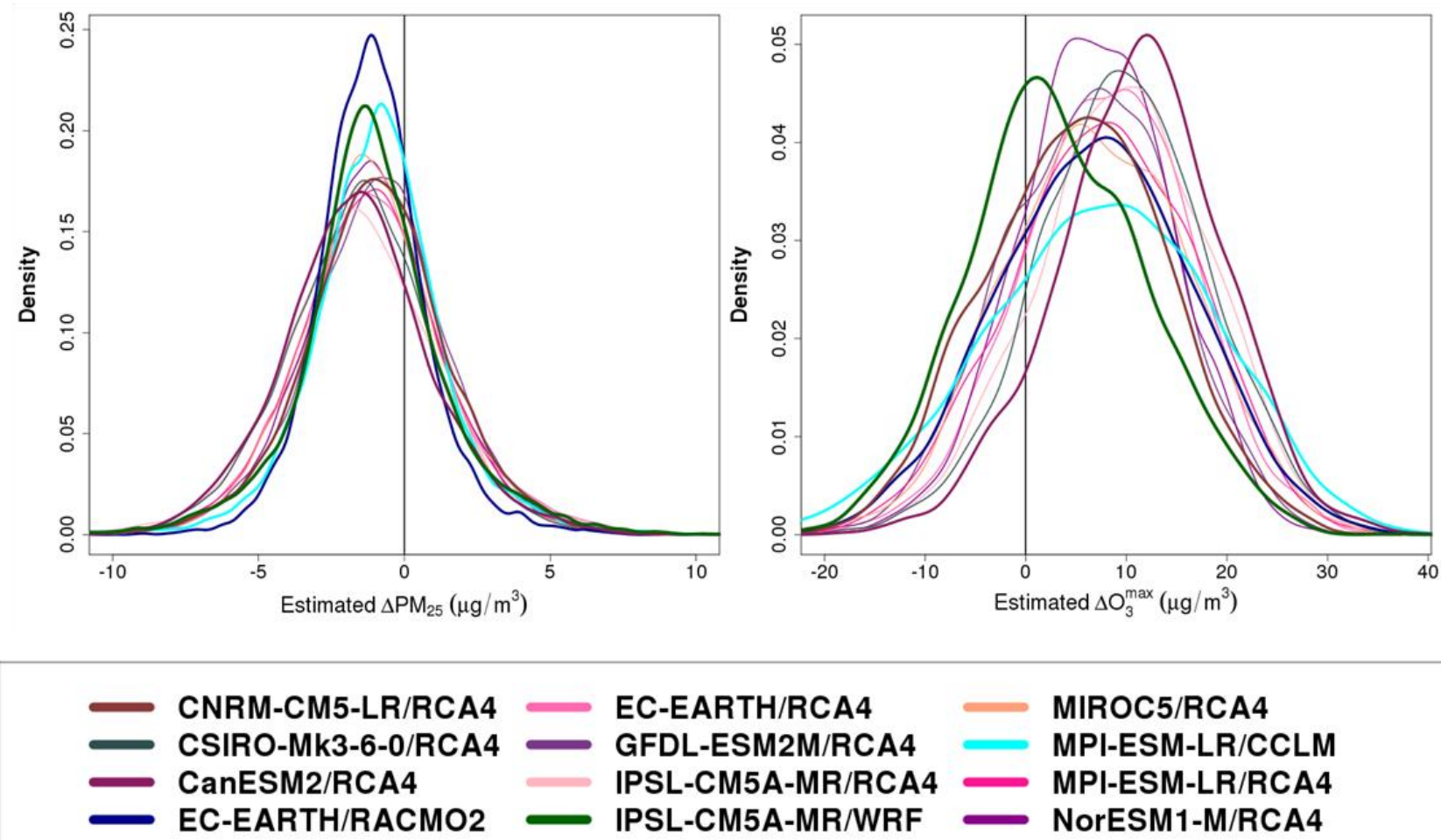

EC-EARTH/RCA4 GFDL-ESM2M/RCA4 IPSL-CM5A-MR/RCA4 IPSL-CM5A-MR/WRF
MIROC5/RCA4 MPI-ESM-LR/CCLM MPI-ESM-LR/RCA4 NorESM1-M/RCA4

2 Figure S5: Same as S2 for Northern Italy. 

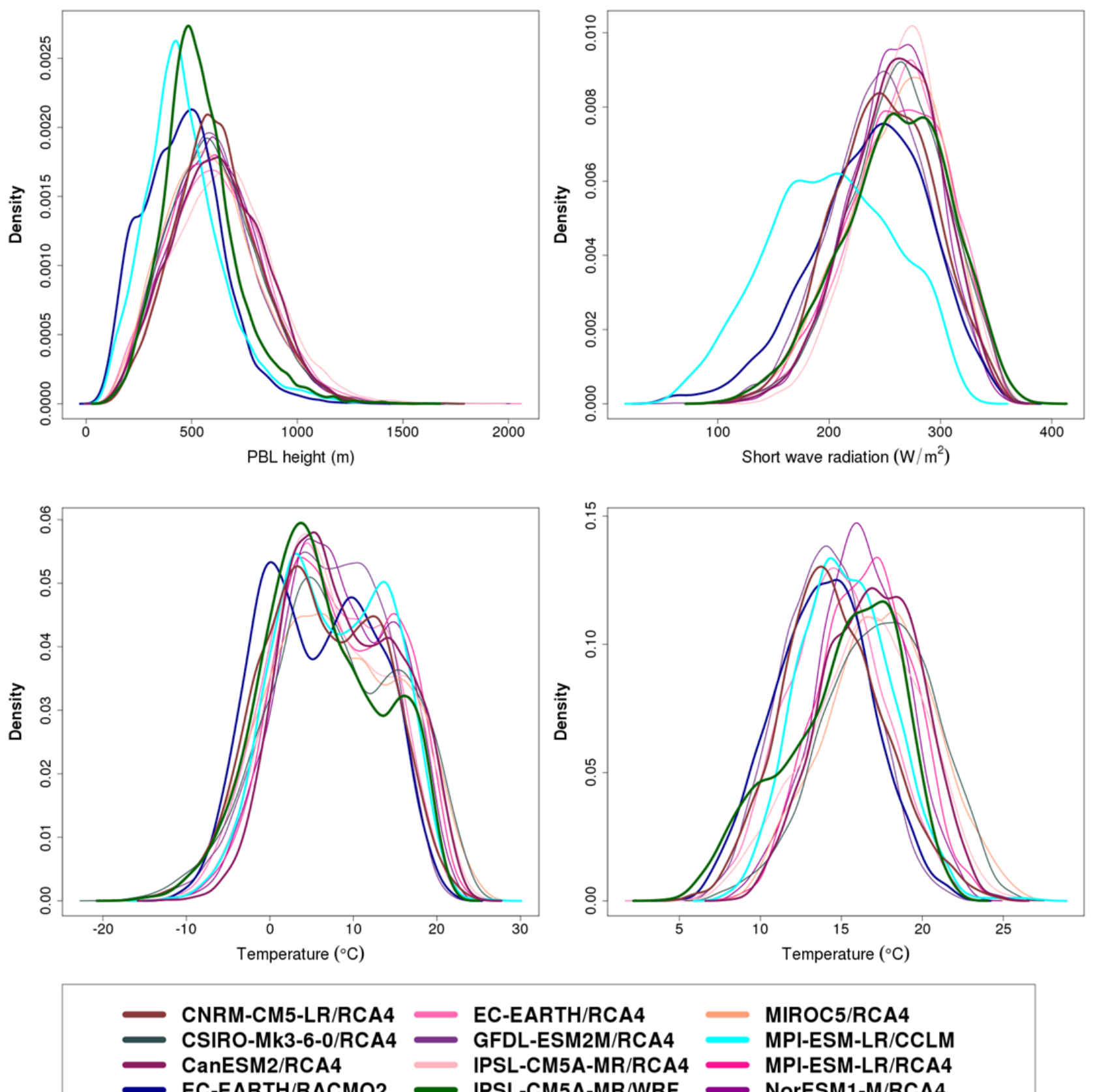

Figure S6: Same as S3 for Northern Italy. 

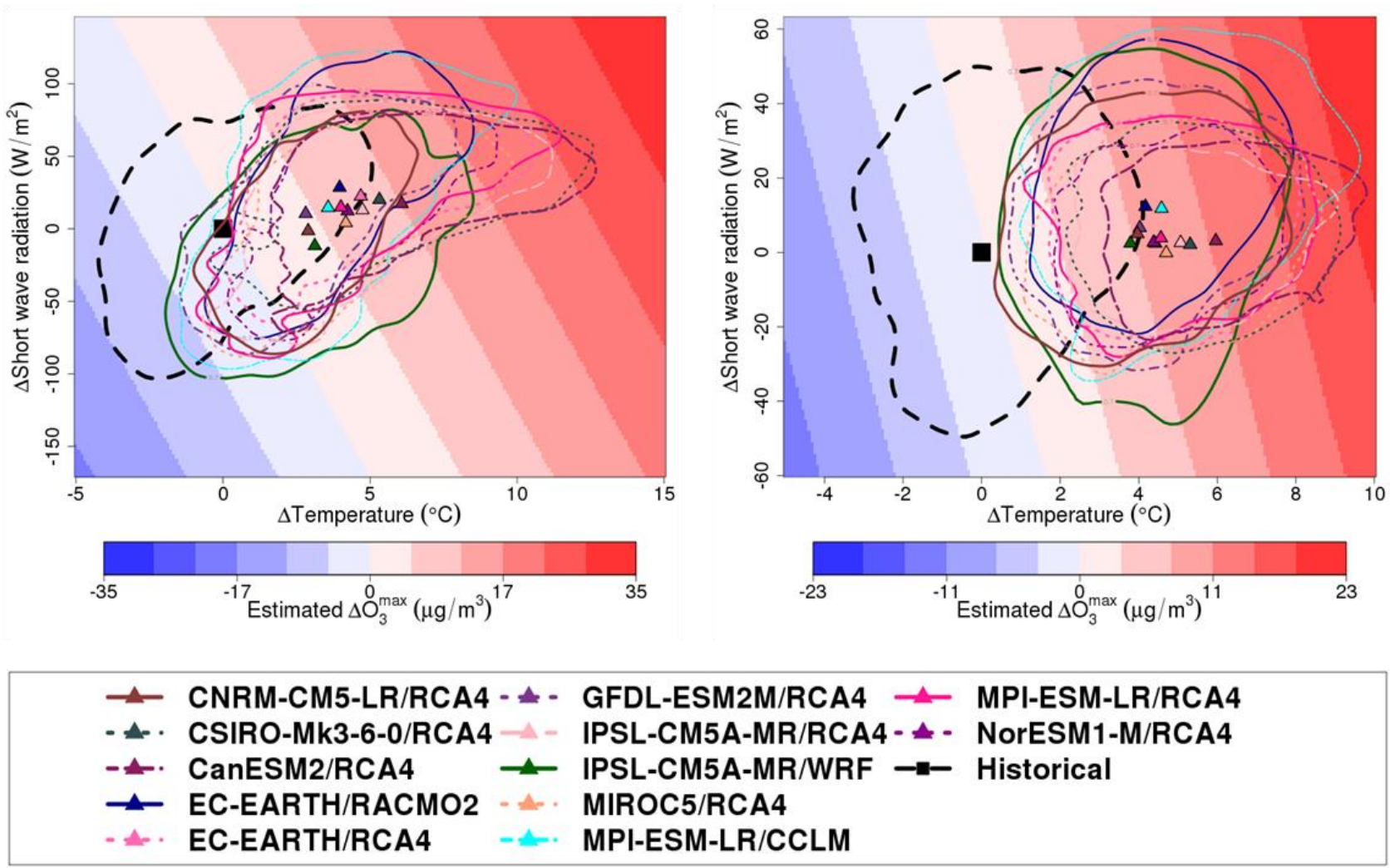

3 Figure S7: The left figure presents the proxy of ensemble projections for daily maximum de-seasonnalised summer ozone for France. The right figure represents the same for Iberian Peninsula. For both figures, the shaded background represents the evolution of pollutants estimated by the statistical models. The contours are representing the regional climate projections and the triangles their mean. The black dashed contour represents the historical - IPSL-CM5A-MR/WRF - and the square its mean. 

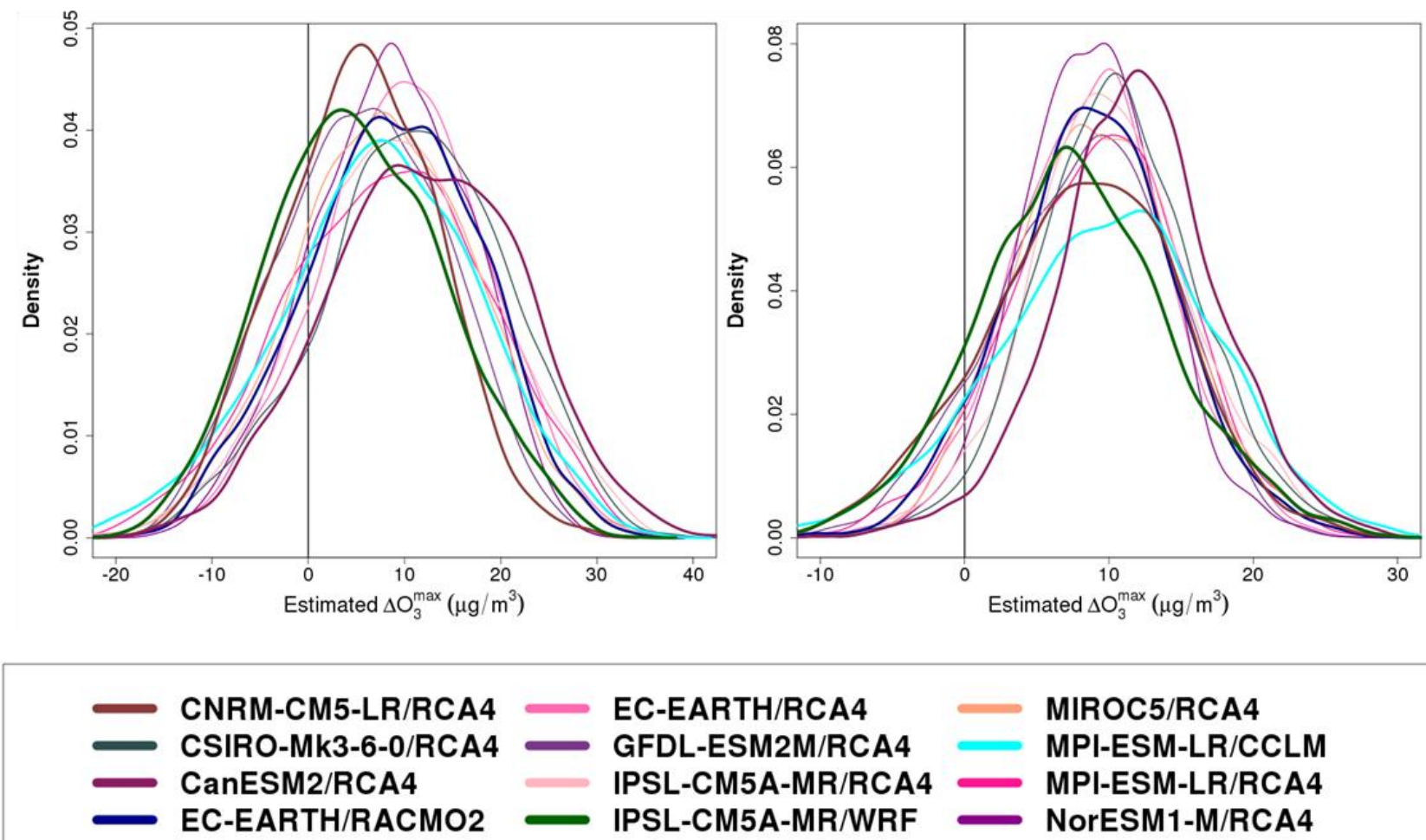

\section{EC-EARTH/RCA4 GFDL-ESM2M/RCA4 IPSL-CM5A-MR/RCA4} MIROC5/RCA4 IPSL-CM5A-MR/WRF MPI-ESM-LR/CCLM MPI-ESM-LR/RCA4 NorESM1-M/RCA4

Figure S8: The left figure represents, for each regional climate model the probability density function (PDF) of the concentrations estimated with the bivariate linear model at the end of the century minus the estimated concentrations of the historical period for daily maximum de-seasonnalised summer ozone in France. The right figure presents the results same for Iberian Peninsula. 

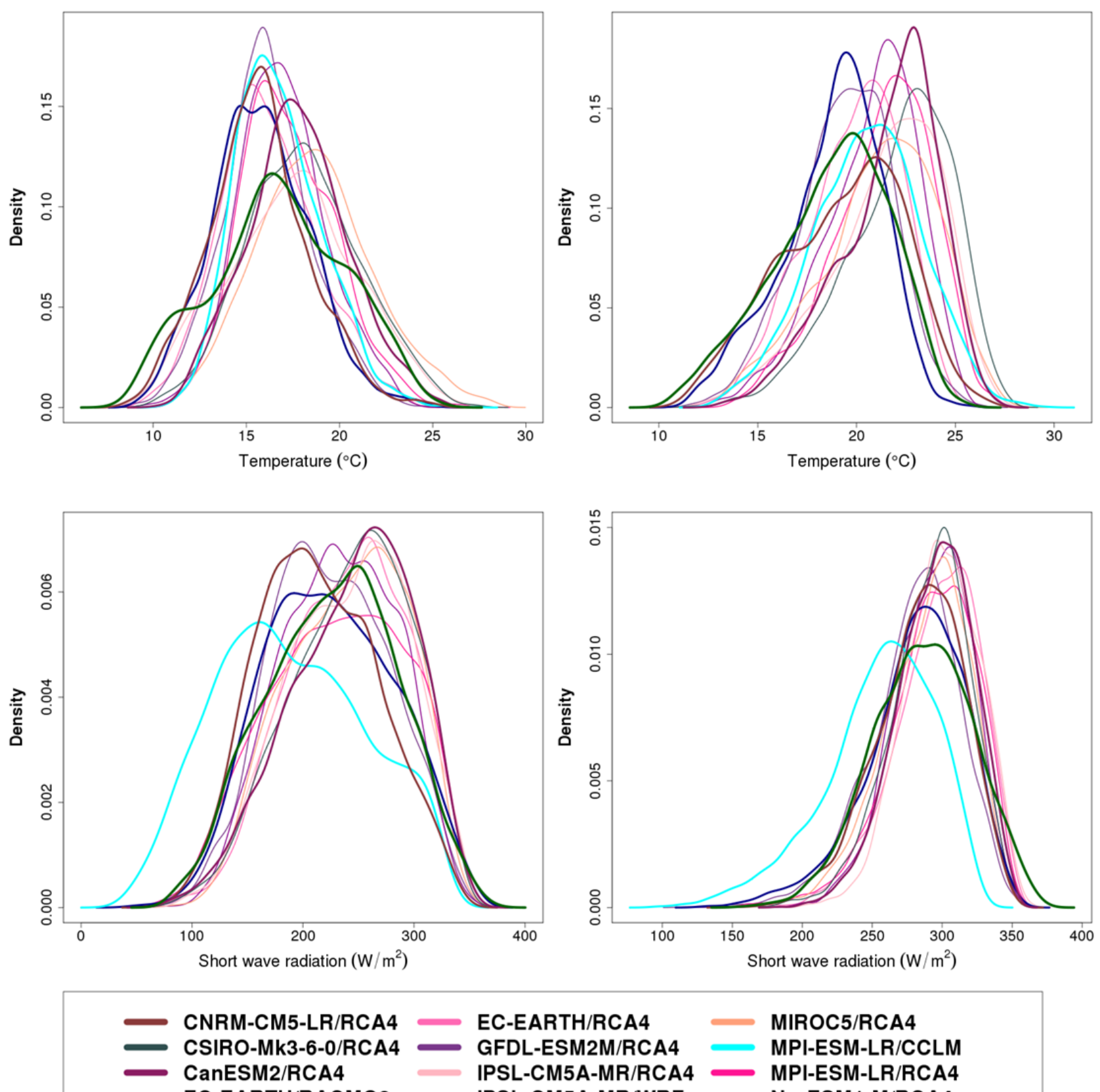

EC-EARTH/RCA4

MIROC5/RCA4

CSIRO-Mk3-6-0/RCA4 GFDL-ESM2M/RCA4

EC-EARTH/RACMO2

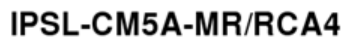

MPI-ESM-LR/CCLM

IPSL-CM5A-MR/RCA4

MPI-ESM-LR/RCA4

IPSL-CM5A-MR/WRF NorESM1-M/RCA4

3 Figure S9: The first column of the panel represents the historical JJA distribution of the meteorological

4 variables identified by our statistical models as the two major drivers (a. near surface temperature; $\mathbf{b}$.

5 incoming short wave radiation) for summer ozone in France. The second column represents the same for

Iberian Peninsula (a. near surface temperature; b. incoming short wave radiation). 